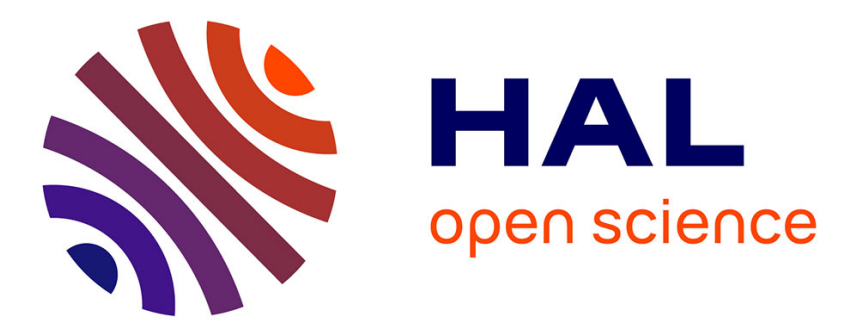

\title{
Diborene: Generation and Photoelectron Spectroscopy of an Inorganic Biradical
}

Domenik Schleier, Alexander Humeniuk, Engelbert Reusch, Fabian Holzmeier,

Dianailys Nunez-Reyes, Christian Alcaraz, Gustavo Garcia, Jean-Christophe Loison, Ingo Fischer, Roland Mitric

\section{To cite this version:}

Domenik Schleier, Alexander Humeniuk, Engelbert Reusch, Fabian Holzmeier, Dianailys Nunez-Reyes, et al.. Diborene: Generation and Photoelectron Spectroscopy of an Inorganic Biradical. Journal of Physical Chemistry Letters, 2018, 9 (20), pp.5921-5925. 10.1021/acs.jpclett.8b02338 . hal-02319316

\section{HAL Id: hal-02319316 https://hal.science/hal-02319316}

Submitted on 13 Jan 2021

HAL is a multi-disciplinary open access archive for the deposit and dissemination of scientific research documents, whether they are published or not. The documents may come from teaching and research institutions in France or abroad, or from public or private research centers.
L'archive ouverte pluridisciplinaire HAL, est destinée au dépôt et à la diffusion de documents scientifiques de niveau recherche, publiés ou non, émanant des établissements d'enseignement et de recherche français ou étrangers, des laboratoires publics ou privés. 
Subscriber access provided by University of Sunderland

\section{Clusters, Radicals, and lons; Environmental Chemistry}

\section{Diborene: Generation and Photoelectron Spectroscopy of an Inorganic Biradical}

Domenik Schleier, Alexander Humeniuk, Engelbert Reusch, Fabian Holzmeier, Dianailys NunezReyes, Christian Alcaraz, Gustavo A. Garcia, Jean-Christophe Loison, Ingo Fischer, and Roland Mitric J. Phys. Chem. Lett., Just Accepted Manuscript • DOI: 10.1021/acs.jpclett.8b02338 • Publication Date (Web): 20 Sep 2018

Downloaded from http://pubs.acs.org on September 27, 2018

\section{Just Accepted}

"Just Accepted" manuscripts have been peer-reviewed and accepted for publication. They are posted online prior to technical editing, formatting for publication and author proofing. The American Chemical Society provides "Just Accepted" as a service to the research community to expedite the dissemination of scientific material as soon as possible after acceptance. "Just Accepted" manuscripts appear in full in PDF format accompanied by an HTML abstract. "Just Accepted" manuscripts have been fully peer reviewed, but should not be considered the official version of record. They are citable by the Digital Object Identifier (DOI@). "Just Accepted" is an optional service offered to authors. Therefore, the "Just Accepted" Web site may not include all articles that will be published in the journal. After a manuscript is technically edited and formatted, it will be removed from the "Just Accepted" Web site and published as an ASAP article. Note that technical editing may introduce minor changes to the manuscript text and/or graphics which could affect content, and all legal disclaimers and ethical guidelines that apply to the journal pertain. ACS cannot be held responsible for errors or consequences arising from the use of information contained in these "Just Accepted" manuscripts. 


\title{
Diborene: Generation and Photoelectron
}

\section{Spectroscopy of an Inorganic Biradical}

\author{
Domenik Schleier, ${ }^{a}$ Alexander Humeniuk, ${ }^{a}$ Engelbert Reusch ${ }^{a}$ Fabian Holzmeier, ${ }^{c}$ Dianailys \\ Nunez-Reyes, ${ }^{b}$ Christian Alcaraz, ${ }^{d}$ Gustavo A. Garcia, ${ }^{e}$ Jean-Christophe Loison, ${ }^{b}$ Ingo Fischer, ${ }^{*}$ \\ ${ }^{a}$ and Roland Mitric*, ${ }^{a}$. \\ ${ }^{a}$ D. Schleier, A. Humeniuk, E. Reusch, Prof. Dr. I. Fischer, Prof. Dr. R. Mitric, Institute of
} Physical and Theoretical Chemistry, University of Würzburg, Am Hubland, D-97074 Würzburg

${ }^{b}$ D. N. Reyes, Dr. J.-C. Loison, ISM-CNRS, Université de Bordeaux, 351 cours de la Libération, F-33405 Talence

${ }^{\mathrm{c}}$ Dr. F. Holzmeier, Institut des Sciences Moléculaires d'Orsay, CNRS, Bât. 520 Université Paris-Sud and Paris-Saclay, F-91405 Orsay Cedex

${ }^{\text {d }}$ Dr. C. Alcaraz, LCP, UMR 800, CNRS-Univ. Paris-Sud and Paris Saclay, Bât. 350, Centre Universitaire Paris-Sud, F-91405 Orsay Cedex

${ }^{\text {e }}$ Dr. G. A. Garcia, Synchrotron SOLEIL, L'Orme des Merisiers, St Aubin, B.P. 48, F-91192 Gif sur Yvette

\section{Corresponding Authors}

* Ingo Fischer, e-mail: ingo.fischer@uni-wuerzburg.de,

* Roland Mitric, roland.mitric@uni-wuerzburg.de 


\begin{abstract}
Diborenes, R-BB-R' are of current interest in inorganic chemistry, because they offer the opportunity to tune the properties of a biradical by modifying the substituents of the diborene parent, $\mathrm{HBBH}$. Here we synthesize the elusive diborene by $\mathrm{H}$-atom abstraction from diborane, $\mathrm{B}_{2} \mathrm{H}_{6}$ using fluorine atoms and report a vibrationally resolved photoelectron spectrum of the HBBH biradical. The spectrum is interpreted by comparison with high-level ab initio computations, taking into account the Renner-Teller splitting in the $\mathrm{X}^{+2} \Pi$ ionic ground state, which show an excellent agreement with the experimental spectrum. An adiabatic ionization energy of $9.080 \pm 0.015 \mathrm{eV}$ was determined and a vibrational progression in the boron-boron stretching vibration of $0.14 \mathrm{eV}$ is visible. This is due to the reduction of bond order upon ionization, accompanied by an increase of the computed boron-boron bond length $\mathrm{R}_{\mathrm{BB}}$ from $1.514 \AA$ to $1.606 \AA$.
\end{abstract}

\title{
TOC GRAPHICS
}

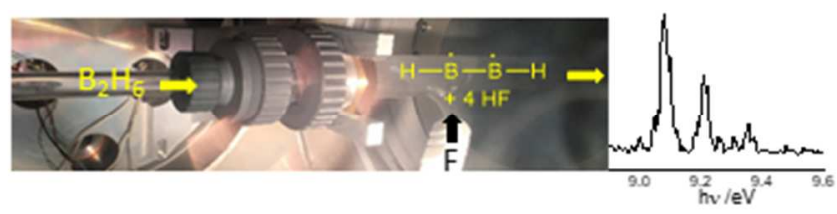

KEYWORDS ionization energy, ab initio calculations, gas phase reaction, synchrotron radiation 
Inorganic biradicals receive increasing attention due to their unusual binding properties that are still a challenge for theory, ${ }^{1}$ but also due to the difficulties to prepare them. Diborenes R-BB-R constitute particularly interesting candidates, because varying the ligands provides the opportunity to tune the properties of the biradicalic HBBH parent, which has the same number of electrons as $\mathrm{C}_{2}$. Only recently the synthesis and characterization of double-bond-containing species based on boron, as well as their fully twisted diradical congeners was reported. ${ }^{2}$ Such biradicals expand the wealth of binding motives ${ }^{3}$ in boron chemistry that range from stabilized diborenes with $\mathrm{B}=\mathrm{B}$ double $\mathrm{e}^{4-6}$ and diborynes with triple bonds ${ }^{7-11}$ to singlet borylenes ${ }^{12}$ and larger boron clusters including fullerene-type structures. ${ }^{13}$ However, in contrast to their organic counterparts, ${ }^{14}$ accurate spectroscopic studies of inorganic reactive intermediates that yield structural and thermochemical information are scarce and in particular the diborene parent compound HBBH (1 in scheme 1) has remained almost elusive so far. The molecule has only been observed in rare gas matrices, where EPR (electron paramagnetic resonance) spectra indicated a triplet ground state ${ }^{15}$ and an IR-spectrum revealed the $v_{3}$ antisymmetric stretch at $2679.9 \mathrm{~cm}^{-1} \cdot{ }^{16}$ Previous photoion yield spectra gave approximate ionization and appearance energies for $\mathrm{B}_{2} \mathrm{H}_{4}{ }^{17}$ and $\mathrm{B}_{2} \mathrm{H}_{5},{ }^{18}$ but no data on smaller $\mathrm{B}_{\mathrm{x}} \mathrm{H}_{\mathrm{y}}$ species were reported. Here we present a vibrationally resolved photoelectron spectrum of diborene 1, obtained by photoionization with synchrotron radiation (SR). The experiments are complemented by highlevel ab initio computations. A large number of theoretical studies are available for the neutral ground state of $\mathbf{1},{ }^{19-22}$ also focusing on the EPR properties ${ }^{23}$ and most recently on the competition between multicenter and classical bonding. ${ }^{24}$ However, no computations of the Renner-Tellersplit cation have yet been reported. 


\section{$\mathrm{B}_{2} \mathrm{H}_{6}+4 \mathrm{~F} \cdot \longrightarrow \mathrm{H}-\dot{\mathrm{B}}-\dot{\mathrm{B}}-\mathrm{H}+4 \mathrm{HF}$}

2

Scheme 1. Diborene 1 was produced from diborane 2 by the reaction with fluorine atoms.

Diborene 1 is a linear molecule of $\mathrm{D}_{\infty \mathrm{h}}$ symmetry with a ${ }^{3} \Sigma_{\mathrm{g}}{ }^{-}$ground state. ${ }^{23}$ The highest singly occupied molecular orbitals (SOMO) are the $\left[1 \pi_{\mathrm{u}}\left(\mathrm{p}_{\mathrm{x}}\right)\right]^{1}\left[1 \pi_{\mathrm{u}} \mathrm{p}_{\mathrm{y}}\right]^{1}$ binding orbitals, so the formal bond order is 2 . However, since the unpaired electrons are situated in orthogonal MOs, the double bond used in a Lewis-description is questionable in MO theory and therefore omitted from Scheme 1.

Diborene 1 was produced from diborane $\mathbf{2}$ according to Scheme 1 by reaction with fluorine atoms, generated in a microwave discharge from $F_{2}$. The driving force for this reaction is the large binding energy of HF $\left(D_{\mathrm{e}}=592 \mathrm{~kJ} / \mathrm{mol}\right) .{ }^{25} \mathrm{H}$-abstraction by $\mathrm{F}$-atoms has been utilized before to record photoelectron spectra of reactive intermediates, ${ }^{26,27}$ but application has been limited by the unselectivity of the approach. In fact, the reaction with fluorine atoms produces a range of $\mathrm{B}_{\mathrm{x}} \mathrm{H}_{\mathrm{y}}$ species, with the maximum of the distribution depending on the F-concentration, as demonstrated in Figure 1. We therefore applied photoelectron-photoion coincidence spectroscopy (PEPICO), ${ }^{28}$ a method that permits to record mass-selected photoelectron spectra (ms-PES) for each composition by correlating ions and electrons. Several reactive molecules generated by fluorine discharges, ${ }^{29,30}$ pyrolysis $^{31-35}$ or photolysis ${ }^{36}$ have been studied using PEPICO, which is evolving into an analytical tool to probe elusive intermediates for example in model flames, ${ }^{37,38}$ catalytic reactors ${ }^{39}$ and kinetics experiments. ${ }^{36,40}$ 


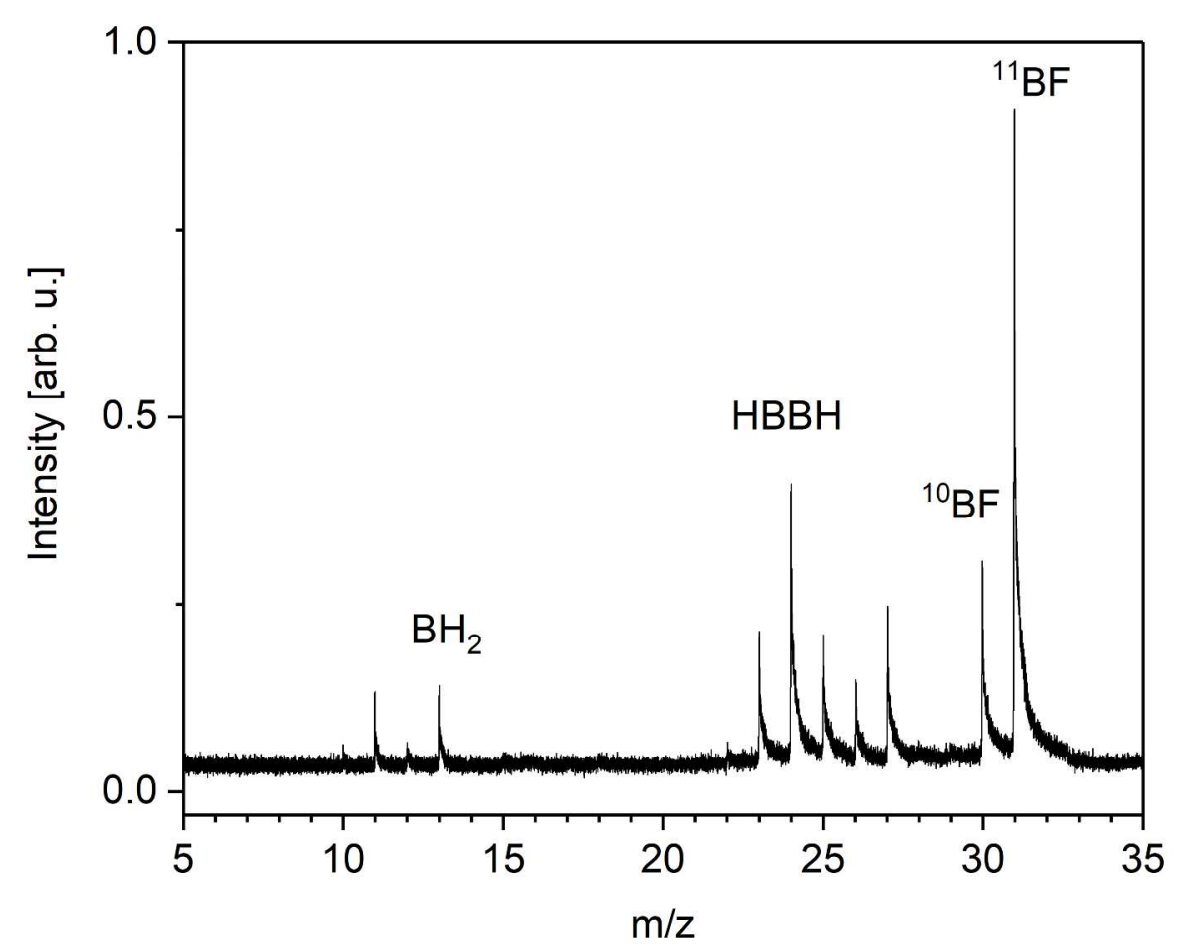

Figure 1. The mass spectrum of $\mathrm{B}_{2} \mathrm{H}_{6}$ in a fluorine discharge.

Figure 1 depicts a mass spectrum, integrated over all photon energies from 8.5 to $11.4 \mathrm{eV}$ to show all species present in the reactor. The presence of a large number of different molecules demonstrates the need for mass-selection, i.e. coincidence detection of electrons and ions. The spectrum is dominated by BF, which is efficiently formed due to the strong boron-fluorine bond. The molecule has been investigated by Dyke and coworkers, who reported an IE of $11.12 \pm 0.01$ $\mathrm{eV}$ for the transition into the $\mathrm{X}^{+}{ }^{2} \Sigma^{+}$ground state of the cation. ${ }^{41}$ Beside $\mathrm{BF}$ a number of $\mathrm{B}_{2} \mathrm{H}_{\mathrm{y}}$ compounds are visible. The experimental conditions were chosen to maximize $\mathrm{B}_{2} \mathrm{H}_{2}$. As visible, $\mathrm{BH}_{2}$ is present as well, but the intensity was not sufficient to record a photoelectron spectrum. In addition we observed peaks corresponding to $\mathrm{B}_{4} \mathrm{H}_{\mathrm{y}}$, which originate from boron-clusters that have formed in the sample. 


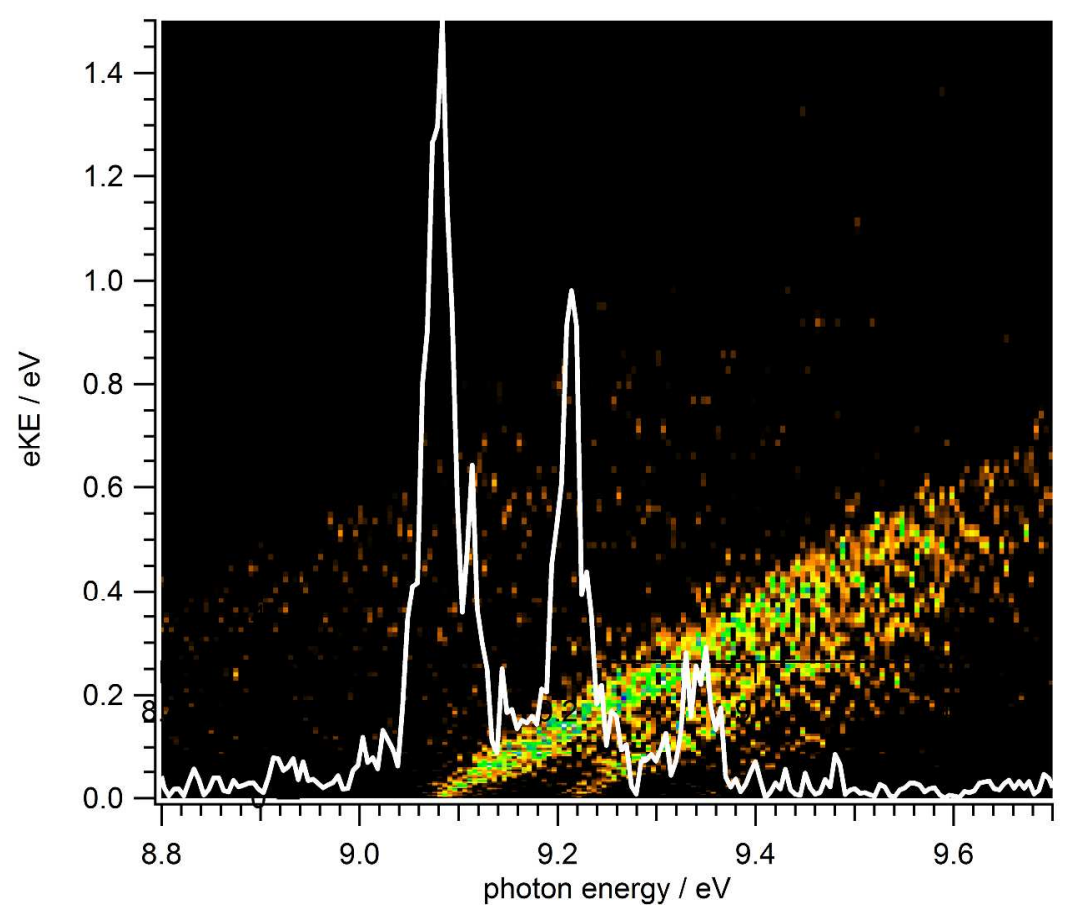

Figure 2. Full photoelectron spectrum matrix of the $m / z=24$ mass channel. Note that around 9.65 $\mathrm{eV}$ the amount of sample started to decrease.

The photoelectron signal in the $\mathrm{m} / \mathrm{z}=24$ mass channel, corresponding to $\mathbf{1}$ as a function of electron kinetic energy (eKE) and photon energy is shown as a two-dimensional color (intensity) maps representing the PES- (Photoelectron Spectrum) matrix in Figure 2. From the matrix the slow photoelectron spectrum (SPES) can be obtained by integrating the photoelectron signal along diagonal lines of constant slope $\mathrm{eKE}=\mathrm{h} v$ - IE, following the procedure outlined previously. ${ }^{30,42}$ This yields the mass-selected slow photoelectron spectrum (ms-SPES), given as a white line in Figure 2, which is associated with a resolution comparable to the more common threshold PES, but with a higher signal-to-noise ratio.

The ms-SPES of $\mathbf{1}$ is shown in more detail in the upper trace of Figure 3. Note that contributions from ${ }^{10} \mathrm{~B}^{11} \mathrm{BH}_{3}$ will appear in the $\mathrm{m} / \mathrm{z}=24$ mass channel, but can be identified by comparison with 
the ${ }^{11} \mathrm{~B}_{2} \mathrm{H}_{3}$ spectrum recorded in the $\mathrm{m} / \mathrm{z}=25$ channel. In addition small contributions from ${ }^{10} \mathrm{~B}_{2} \mathrm{H}_{4}$ might appear. We computed the IE for three isomers of $\mathrm{B}_{2} \mathrm{H}_{4}$ using the CBS-QB3 composite method and arrived at values of $10.38 \mathrm{eV}\left(\mathrm{H}_{2} \mathrm{~B}-\mathrm{BH}_{2}\right), 9.57 \mathrm{eV}$ (bridged structure I, $\mathrm{HB}(\mathrm{H})_{2} \mathrm{BH}$ ) and $8.43 \mathrm{eV}$ (bridged structure II, $\left.\mathrm{B}(\mathrm{H})_{3} \mathrm{BH}\right)$. The FC simulation of bridged structure 1 shows a long progression with a weak origin band, maximizing at the second overtone. Thus contributions from ${ }^{10} \mathrm{~B}_{2} \mathrm{H}_{4}$ to the spectrum can be excluded. A contribution of the higher energy isomer $\mathrm{BBH}_{2}$ to $\mathrm{m} / \mathrm{z}=24$ has also to be considered. The IE was calculated to be $8.97 \mathrm{eV}$, but again a different vibrational progression is expected from a Franck-Condon simulation.

The first band in Figure 3 at $9.08 \pm 0.015 \mathrm{eV}$ corresponds to the adiabatic ionization energy $\mathrm{IE}_{\mathrm{ad}}$ of $\mathrm{HBBH}$. The error bars are taken from the full width at half maximum of the first band and reflect the underlying rotational distribution. No significant hot band activity is apparent, indicating that the molecules are approximately at room temperature. A rotational temperature of $200 \mathrm{~K}$ is deduced from the molecular beam velocity, which is extracted from the ion image. The vibrational temperature might be slightly higher, but the small hot band intensity shows that the exothermicity of the $\mathrm{H}$ atom abstraction is mostly taken up by the HF vibration. At higher energies a vibrational progression with a spacing of $0.14 \mathrm{eV}$ appears that can be qualitatively explained within molecular orbital theory: Upon photoionization an electron is removed from the $1 \pi_{\mathrm{u}}$ binding orbital, the bond order is reduced from 2 to 1.5 , and the boron-boron-bond length $\mathrm{R}_{\mathrm{BB}}$ will increase. Consequently, activity in the BB-stretching vibration is expected. 


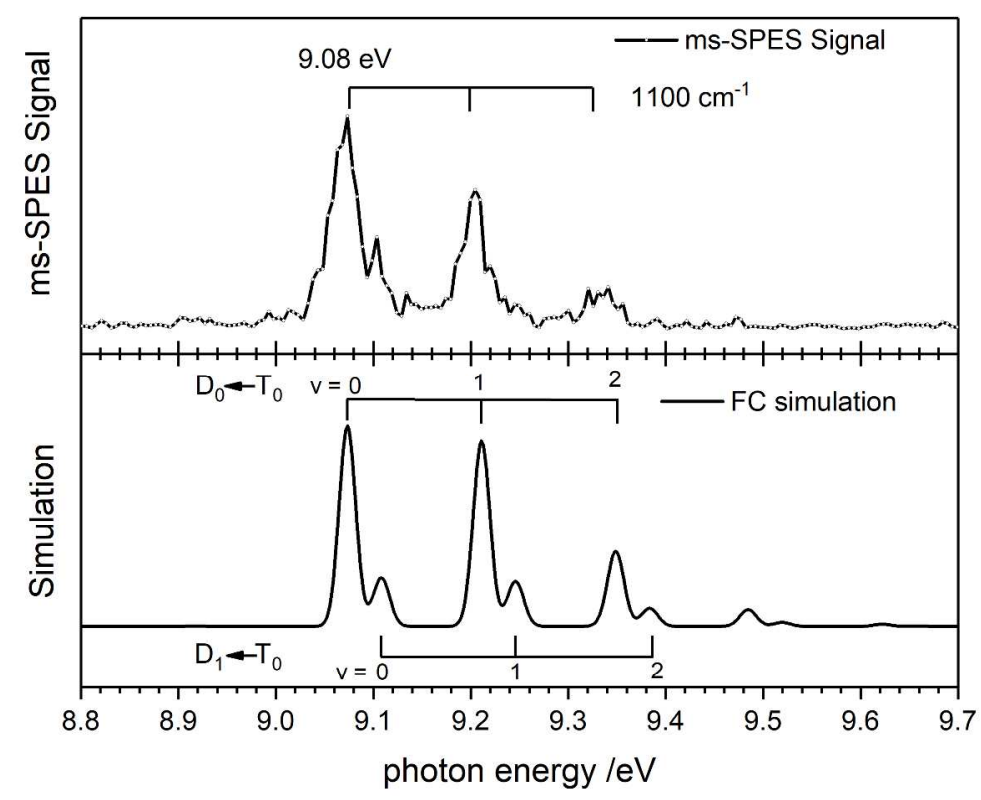

Figure 3. Experimental (upper trace) and computed photoelectron spectrum of HBBH. The computed spectrum was shifted by $0.195 \mathrm{eV}$ to achieve the best match with the experiment.

However, analysis is impeded by the fact that the ionic ground state is a doubly degenerate ${ }^{2} \Pi$ state, which exhibits Renner-Teller splitting. Complete active space multireference configuration interaction (CAS-MRCI) computations show that the two components (called $\mathrm{D}_{0}$ and $\mathrm{D}_{1}$ below for simplicity) are isoenergetic at the linear geometry. The degeneracy is lifted by excitation of a bending motion, but the minimum energy geometry remains linear. While for the totally symmetric vibrational mode $v_{1}$ a wavenumber of $1108 \mathrm{~cm}^{-1}(0.137 \mathrm{eV})$ was computed for both $\mathrm{D}_{0}$ and $\mathrm{D}_{1}$, the bending mode energies are slightly higher in $\mathrm{D}_{1}$. Therefore the latter state has a higher zero point energy (4801 cm $\mathrm{cm}^{-1}$ compared to $4518 \mathrm{~cm}^{-1}$ ), which should lead to the appearance of two progressions in the PES. This is evident from the Franck-Condon simulation based on the computations depicted in the lower trace of Figure 3. The two progressions cannot be fully resolved in the experimental spectrum, but the bands show a shoulder at the high-energy 
side, which is assigned to the $\mathrm{T}_{0} \rightarrow \mathrm{D}_{1}$ transition. Nevertheless, the agreement between experiment and simulation is excellent and both the $v_{1}$ vibrational spacing and the intensities are well reproduced, indicating that the computations accurately reflect both the geometry change upon photoionization and the shape of the cationic potential energy surfaces. $\mathrm{IE}_{\mathrm{ad}}$ was computed to be $8.865 \mathrm{eV}$, i.e. roughly $0.2 \mathrm{eV}$ lower than the experimental value. A bond length $\mathrm{R}_{\mathrm{BB}}$ of $1.514 \AA$ was computed for the $\mathrm{X}^{3} \Sigma_{\mathrm{g}}{ }^{-}$state, comparable to $\mathrm{B}=\mathrm{B}$ double bonds. ${ }^{6}$ For the $\mathrm{X}^{+}{ }^{2} \Pi$ state $\mathrm{R}_{\mathrm{BB}}=1.606 \AA$ was found, thus the bond length increases by almost $0.1 \AA$ upon ionization. Note that previous MRCI computations found slightly shorter $\mathrm{R}_{\mathrm{BB}}$ for the neutral ground state. ${ }^{19-}$ ${ }^{21}$ The most important parameters are summarized in table 1. 
Table 1. Important parameters for diborene $\mathbf{1 .}$

\begin{tabular}{lllll}
\hline & $\mathrm{X}^{3} \Sigma_{\mathrm{g}}^{-[\mathrm{a}]}$ & $\mathrm{X}^{+2} \Pi\left(\mathrm{D}_{0}\right)^{[\mathrm{a}]}$ & $\mathrm{X}^{+2} \Pi\left(\mathrm{D}_{1}\right)^{[\mathrm{a}]}$ & Experiment \\
\hline $\mathrm{R}_{\mathrm{BB}} / \AA$ & 1.514 & 1.606 & 1.606 & \\
$v_{1} / \mathrm{eV}$ & 0.156 & 0.137 & 0.137 & 0.14 \\
$\mathrm{ZPE} / \mathrm{eV}$ & 0.576 & 0.560 & 0.595 & \\
$\mathrm{IE}_{\mathrm{ad}} / \mathrm{eV}$ & 8.865 & & & $9.08 \pm 0.015$ \\
\hline
\end{tabular}

[a] CAS-MRCI computations

In conclusion we report the gas phase synthesis and the first photoelectron spectrum of diborene, a prototype inorganic biradical, yielding an $\mathrm{IE}_{\mathrm{ad}}=9.08 \mathrm{eV}$. Excellent agreement with high-level computations is observed. Despite the tendency of boron to form strong B-F bonds, HBBH was formed in sufficient concentration to record a vibrationally resolved photoelectron spectrum. The work represents a cornerstone for systematic studies of the effects that changes in the substitution pattern have on the electronic stability of diborenes.

\section{Methods}

Experiments were conducted at the DESIRS undulator beamline ${ }^{43}$ of the SOLEIL storage ring in St. Aubin/F, using the DELICIOUS 3 double imaging photoelectron/photoion coincidence (i2PEPICO) spectrometer. ${ }^{44} \mathrm{HBBH}$ was generated from $\mathrm{B}_{2} \mathrm{H}_{6}(0.5 \%$ in $\mathrm{Ar})$ via $\mathrm{H}$-abstraction by fluorine according to Scheme 1 in a fast flow tube at low pressure that is described in detail elsewhere. ${ }^{45}$ Fluorine atoms were produced in a microwave discharge of a mixture of around $5 \%$ 
$\mathrm{F}_{2}$ diluted in $\mathrm{He}$, introduced into the flow tube $50 \mathrm{~cm}$ before the reaction zone. The amount of $\mathrm{F}_{2}$ was adjusted to maximize the signal of $\mathbf{1}$, the Fluorine atom density being typically around $10^{13}$ atoms $\cdot \mathrm{cm}^{-3}$. After passage through the flow tube, the mixture is adiabatically expanded through a first skimmer into a differentially pumped chamber (few $10^{-4} \mathrm{mbar}$ ), and through a second skimmer ( $\mathrm{f}=1 \mathrm{~mm}$, Beam Dynamics Inc.) into the ionization chamber (few $10^{-8} \mathrm{mbar}$ ). The VUV radiation was provided by a variable polarization undulator, which feeds the DESIRS beamline. Radiation with a narrow bandwidth was selected by a $6.65 \mathrm{~m}$ normal incidence monochromator with a $200 \mathrm{~g} / \mathrm{mm} \mathrm{SiC} \mathrm{grating} \mathrm{and} \mathrm{focused} \mathrm{onto} \mathrm{a} \mathrm{200/200} \mu \mathrm{m}(\mathrm{H} / \mathrm{V})$ spot at the ionization region. The entrance and exit slits were set to yield a resolution of around $5 \mathrm{meV}$ at 9 $\mathrm{eV}$ for a flux of $2 \times 10^{12}$ photons/s. A gas filter filled with $0.25 \mathrm{mbar}$ Ar cut off the higher order radiation from the undulator. ${ }^{46}$ The photon energy was scanned in $5 \mathrm{meV}$ steps and data were averaged for $300 \mathrm{~s}$ at each energy. Photoelectron spectra were obtained via the slow PES (SPES) technique described in Ref. ${ }^{42}$ The spectral resolution is around $20 \mathrm{meV}$.

Electronic structure calculations were performed at the CAS-MRCI level with the ANO-RCC basis set using the software package MOLPRO. ${ }^{47}$ The orbitals of an active space consisting of 10 electrons in 10 orbitals were optimized by minimizing the energy of one triplet and two ionic doublet states. This was followed by multireference CI calculations with the same active space to find the lowest triplet and the lowest two ionic doublet states. Geometry optimizations in the $\mathrm{T}_{0}$, $\mathrm{D}_{0}$ and $\mathrm{D}_{1}$ states at the same level of theory were followed by a frequency calculation. All 7 vibrational frequencies were positive and the remaining 5 frequencies were 0 within numerical precision. The Franck-Condon factors were computed using the pGopher program, ${ }^{48}$ including Duschinsky rotation. 
ACKNOWLEDGMENTS: This work was performed on the DESIRS beamline under Proposal No. 20170009. We acknowledge SOLEIL for provision of synchrotron radiation facilities and the DESIRS beamline team for their assistance. The work was financially supported by the Deutsche Forschungsgemeinschaft, research training school GRK 2112 (Molecular Biradicals) as well as Fi 575/13-1 and the Agence Nationale de la Recherche (ANR) under grant number ANR12- BS08-0020-02 (project SYNCHROKIN). We would like to thank Maik Finze (University of Würzburg) for providing the $\mathrm{B}_{2} \mathrm{H}_{6}$ sample.

\section{REFERENCES}

(1) Miliordos, E.; Ruedenberg, K.; Xantheas, S. S. Unusual Inorganic Biradicals: A Theoretical Analysis. Angew. Chem. Int. Ed. 2013, 52, 5736-5729.

(2) Böhnke, J.; Dellermann, T.; Celik, M. A.; Krummenacher, I.; Dewhurst, R. D.; Demeshko, S.; Ewing, W. C.; Hammond, K.; Heß, M.; Bill, E.; Welz, E.; Röhr, M. I. S.; Mitrić, R.; Engels, B.; Meyer, F.; Braunschweig, H. Isolation of Diborenes and their $90^{\circ}$-Twisted Diradical Congeners. Nature Comm. 2018, 9, 1197.

(3) Braunschweig, H.; Dewhurst, R. D. Single, Double, Triple Bonds and Chains: The Formation of Electron-Precise BB Bonds. Angew. Chem. Int. Ed. 2013, 52, 3574-3583.

(4) Auerhammer, D.; Arrowsmith, M.; Bissinger, P.; Braunschweig, H.; Dellermann, T.; Kupfer, T.; Lenczyk, C.; Roy, D. K.; Schafer, M.; Schneider, C. Increasing the Reactivity of Diborenes: Derivatization of NHC-Supported Dithienyldiborenes with Electron-Donor Groups. Chem. Eur. J. 2018, 24, 266-273.

(5) Braunschweig, H.; Constantinidis, P.; Dellermann, T.; Ewing, W. C.; Fischer, I.; Hess, M.; Knight, F. R.; Rempel, A.; Schneider, C.; Ullrich, S.; Vargas, A.; Woollins, J. D. Highly Strained Heterocycles Constructed from Boron-Boron Multiple Bonds and Heavy Chalcogens. Angew. Chem. Int. Ed. 2016, 55, 5606-5609.

(6) Wang, Y.; Quillian, B.; Wei, P.; Wannere, C. S.; Xie, Y.; King, R. B.; Schaefer, H. F.; Schleyer, P. V.; Robinson, G. H. A Stable Neutral Diborene Containing a B = B Double Bond. J. Am. Chem.Soc. 2007, 129, 12412-12413.

(7) Zhou, M.; Tsumori, N.; Li, Z.; Fan, K.; Andrews, L.; Xu, Q. OCBBCO: A Neutral Molecule with Some Boron-Boron Triple Bond Character. J. Am. Chem.Soc. 2002, 124, 12936-12937.

(8) Braunschweig, H.; Dewhurst, R.; Hammond, K.; Mies, J.; Radacki, K.; Vargas, A. Ambient-Temperature Isolation of a Compound with a Boron-Boron Triple Bond. Science 2012, 336, 120-1422. 
(9) Frenking, G.; Holzmann, N. A Boron-Boron Triple Bond. Science 2012, 336, 1394-1395.

(10) Bohnke, J.; Braunschweig, H.; Constantinidis, P.; Dellermann, T.; Ewing, W. C.; Fischer, I.; Hammond, K.; Hupp, F.; Mies, J.; Schmitt, H. C.; Vargas, A. Experimental Assessment of the Strengths of B-B Triple Bonds. J. Am. Chem.Soc. 2015, 137, 1766-1769.

(11) Li, S. D.; Zhai, H. J.; Wang, L. S. $\mathrm{B}_{2}(\mathrm{BO})_{2}{ }^{2--}$ Diboronyl Diborene: A Linear Molecule with a Triple Boron-Boron Bond. J. Am. Chem.Soc. 2008, 130, 2573-2579.

(12) Bettinger, H. F. Phenylborylene: Direct Spectroscopic Characterization in Inert Gas Matrices. J. Am. Chem.Soc. 2006, 128, 2534-2535.

(13) Zhai, H.-J.; Zhao, Y.-F.; Li, W.-L.; Chen, Q.; Bai, H.; Hu, H.-S.; Piazza, Z. A.; Tian, W.-J.; Lu, H.-G.; Wu, Y.-B.; Mu, Y.-W.; Wei, G.-F.; Liu, Z.-P.; Li, J.; Li, S.-D.; Wang, L.S. Observation of an All-Boron Fullerene. Nature Chem. 2014, 6, 727-731.

(14) Abe, M. Diradicals. Chem. Rev. 2013, 113, 7011-7088.

(15) Knight Jr., L. B.; Kerr, K.; Miller, P. K.; Arrington, C. A. ESR Investigation of the HBBH $\left(\mathrm{X}^{3} \Sigma\right)$ Radical in Neon and Argon Matrices at $4 \mathrm{~K}$. Comparison with ab Initio SCF and CI Calculations. J. Phys. Chem. 1995, 99, 16842-16848.

(16) Tague Jr., T. J.; Andrews, L. Reactions of Pulsed-Laser Evaporated Boron Atoms with Hydrogen. Infrared Spectra of Boron Hydride Intermediate Species in Solid Argon. J. Am. Chem.Soc. 1994, 116, 4970-4976.

(17) Ruscic, B.; Schwarz, M.; Berkowitz, J. Molecular Structure and Thermal Stability of $\mathrm{B}_{2} \mathrm{H}_{4}$ and $\mathrm{B}_{2} \mathrm{H}_{4}+$ Species. J. Chem. Phys. 1989, 91, 4576-4582.

(18) Ruscic, B.; Schwarz, M.; Berkowitz, J. Structure and Bonding in the $\mathrm{B}_{2} \mathrm{H}_{5}$ Radical and Cation. J. Chem. Phys. 1989, 91, 4183-4188.

(19) Miliordos, E.; Mavridis, A. Ab Initio Investigation of the Electronic Structure and Bonding of BH, BH-, and HBBH Molecules. J. Chem. Phys. 2008, 128, 144308.

(20) Peric, M.; Ostojic, B.; Engels, B. Ab Initio Study of the Electronic Spectrum of $\mathrm{B}_{2} \mathrm{H}_{2}$.1. Vertical Spectrum and trans- and cis-Bending Potential Curves. J. Mol. Spec. 1997, 182, 280-294.

(21) Peric, M.; Ostojic, B.; Engels, B. Ab Initio Study of the Electronic Spectrum of $\mathrm{B}_{2} \mathrm{H}_{2}$.2. Potential Curves for Torsional Motion, Symmetric B-H Stretching, and B-B Separation. J. Mol. Spec. 1997, 182, 295-308.

(22) Brites, V.; Leonard, C. Rovibrational energies of $\mathrm{B}_{2} \mathrm{H}_{2}\left(\mathrm{X}^{3} \Sigma^{-\mathrm{g}}\right)$ from an explicitly correlated potential energy surface. Comput. Theor. Chem. 2013, 1025, 24-29.

(23) Engels, B.; Suter, H. U.; Peric, M. Ab Initio Investigation of Vibrational Effects on Magnetic Hyperfine Coupling Constants in the $\mathrm{X}^{3} \Sigma_{\mathrm{g}}{ }^{-}$State of $\mathrm{B}_{2} \mathrm{H}_{2}$. J. Phys. Chem. 1996, 100, 10121-10122.

(24) Lundell, K. A.; Boldyrev, A. I. Tug-of-War Between Classical and Multicenter Bonds in H-(Be)n-H Species. Chem. Phys. Lett. 2018, 699, 85-87.

(25) Peterson, K. A.; Dunning, T. H. Benchmark Calculations with Correlated Molecular Wave Functions. VII. Binding Energy and Structure of the HF Dimer. J. Chem. Phys. 1995, 102, 2032-20141.

(26) Baker, J.; Barnes, M.; Cockett, M. C. R.; Dyke, J. M.; Ellis, A. M.; Feher, M.; Lee, E. P. F.; Morris, A.; Zamanpour, H. Photoelectron Spectroscopy of Unstable Molecules. $J$. Electron Spectrosc. 1990, 51, 487-511. 
(27) West, J. B.; Dyke, J. M.; Morris, A.; Wright, T. G.; Gamblin, S. D. Photoelectron Spectroscopy of Short-Lived Molecules Using Synchrotron Radiation. J. Phys. B -At. Mol. Opt. Phys. 1999, 32, 2763-2782.

(28) Baer, T.; Tuckett, R. P. Advances in Threshold Photoelectron Spectroscopy (TPEA) and Threshold Photoelectron Photoion Coincidence (TPEPICO). Phys. Chem. Chem. Phys. 2017, 19, 9698-9723.

(29) Gans, B.; Holzmeier, F.; Kruger, J.; Falvo, C.; Roder, A.; Lopes, A.; Garcia, G. A.; Fittschen, C.; Loison, J. C.; Alcaraz, C. Synchrotron-Based Valence Shell Photoionization of CH Radical. J. Chem. Phys. 2016, 144, 204307.

(30) Garcia, G. A.; Gans, B.; Krüger, J.; Holzmeier, F.; Röder, A.; Lopes, A.; Fittschen, C.; Alcaraz, C.; Loison, J. C. Valence Shell Threshold Photoelectron Spectroscopy of C3Hx (x =0-3). Phys. Chem. Chem. Phys. 2018, 20, 8707-8718.

(31) Holzmeier, F.; Lang, M.; Hader, K.; Hemberger, P.; Fischer, I. $\mathrm{H}_{2} \mathrm{CN}^{+}$and $\mathrm{H}_{2} \mathrm{CNH}^{+}$: New Insight into the Structure and Dynamics from Mass-Selected Threshold Photoelectron Spectra. J. Chem. Phys. 2013, 138, 214310.

(32) Holzmeier, F.; Lang, M.; Hemberger, P.; Bodi, A.; Schäfer, M.; Dewhurst, R.; Braunschweig, H.; Fischer, I. Photoionization and Pyrolysis of a 1,4-Azaborinine: RetroHydroboration in the Cation and Identification of Novel Organoboron Ring Systems. Chem. Eur. J. 2014, 20, 9683-9692.

(33) Reusch, E.; Holzmeier, F.; Constantinidis, P.; Hemberger, P.; Fischer, I. IsomerSelective Generation and Spectroscopic Characterization of Picolyl Radicals. Angew. Chem. Int. Ed. 2017, 56, 8000-8003.

(34) Steinbauer, M.; Hemberger, P.; Fischer, I.; Bodi, A. Photoionization of $\mathrm{C}_{7} \mathrm{H}_{6}$ and $\mathrm{C}_{7} \mathrm{H}_{5}$ : Observation of the Fulvenallenyl Radical. ChemPhysChem 2011, 12, 1795-1797.

(35) Cunha de Miranda, B. K.; Alcaraz, C.; Elhanine, M.; Noller, B.; Hemberger, P.; Fischer, I.; Garcia, G.; Soldi-Lose, H.; Gans, B.; Viera Mendez, L. A.; Boye-Peronne, S.; Douin, S.; Zabka, J.; Botschwina, P. Threshold Photoelectron Spectroscopy of the Methyl Radical Isotopomers, $\mathrm{CH}_{3}, \mathrm{CH}_{2} \mathrm{D}, \mathrm{CHD}_{2}$ and $\mathrm{CD}_{3}$ : Synergy between VUV Synchrotron Radiation Experiments and Explicitly Correlated Coupled Cluster Calculations. J. Phys. Chem. A 2010, $114,4818-4830$.

(36) Schleier, D.; Constantinidis, P.; Faßheber, N.; Fischer, I.; Friedrichs, G.; Hemberger, P.; Reusch, E.; Sztaray, B.; Voronova, K. Kinetics of the a- $\mathrm{C}_{3} \mathrm{H}_{5}+\mathrm{O}_{2}$ Reaction, Investigated by Photoionization Using Synchrotron Radiation. Phys. Chem. Chem. Phys. 2018, 20, 10721-10731.

(37) Oßwald, P.; Hemberger, P.; Bierkandt, T.; Akyildiz, E.; Köhler, M.; Bodi, A.; Gerber, T.; Kasper, T. In Situ Flame Chemistry Tracing by Imaging Photoelectron Photoion Coincidence Spectroscopy. Rev. Sci. Instrum. 2014, 85, 025101.

(38) Krüger, J.; Garcia, G. A.; Felsmann, D.; Moshammer, K.; Lackner, A.; Brockhinke, A.; Nahon, L.; Kohse-Höinghaus, K. Photoelectron-photoion coincidence spectroscopy for multiplexed detection of intermediate species in a flame. Phys. Chem. Chem. Phys. 2014, 16, 22791-22804.

(39) Hemberger, P.; Custodis, V. B. F.; Bodi, A.; Gerber, T.; van Bokhoven, J. A. Understanding the Mechanism of Catalytic Fast Pyrolysis by Unveiling Reactive Intermediates in Heterogeneous Catalysis. Nature Comm. 2017, 8, 15946. 
(40) Sztaray, B.; Voronova, K.; Torma, K. G.; Covert, K. J.; Bodi, A.; Hemberger, P.; Gerber, T.; Osborn, D. L. CRF-PEPICO: Double Velocity Map Imaging Photoelectron Photoion Coincidence Spectroscopy for Reaction Kinetics Studies. J. Chem. Phys. 2017, 147, 013944.

(41) Dyke, J. M.; Kirby, C.; Morris, A. Study of the Ionization Process BF' $\left(\mathrm{X}^{2} \mathrm{X}^{+}\right)+$ $\mathrm{BF}\left(\mathrm{X}^{1} \mathrm{X}^{+}\right)$by High-temperature Photoelectron Spectroscopy. J. Chem. Soc. Faraday Trans. 1983, 79, 483-490.

(42) Poully, J. C.; Schermann, J. P.; Nieuwjaer, N.; Lecomte, F.; Grégoire, G.; Desfrançois, C.; Garcia, G. A.; Nahon, L.; Nandi, D.; Poisson, L.; Hochlaf, M. Photoionization of 2-Pyridone and 2-Hydroxypyridine. Phys. Chem. Chem. Phys. 2010, 12, 3566-3572.

(43) Nahon, L.; de Oliveira, N.; Garcia, G. A.; Gil, J., -F.; Pilette, B.; Marcouille, O.; Lagarde, B.; Polack, F. DESIRS: A State-of-the-Art VUV Beamline Featuring High resolution and Variable Polarization for Spectroscopy and Dichroism at SOLEIL. J. Synchrotron Rad. 2012, 19, 508-520.

(44) Garcia, G. A.; Cunha de Miranda, B. K.; Tia, M.; Daly, S.; Nahon, L. DELICIOUS III: A Multipurpose Double Imaging Particle Coincidence Spectrometer for Gas Phase Vacuum Ultraviolet Photodynamics Studies. Rev. Sci. Instrum. 2013, 84, 053112.

(45) Garcia, G. A.; Tang, X.; Gil, J.-F.; Nahon, L.; Ward, M.; Batut, S.; Fittschen, C.; Taatjes, C. A.; Osborn, D. L.; Loison, J.-C. Synchrotron-Based Double Imaging Photoelectron/Photoion Coincidence Spectroscopy of Radicals Produced in a Flow Tube: OH and OD. J. Chem. Phys. 2015, 142, 164201.

(46) Mercier, B.; Compin, M.; Prevost, C.; Bellec, G.; Thissen, R.; Dutuit, O.; Nahon, L. Experimental and Theoretical Study of a Differentially Pumped Absorption Gas Cell Used as a Low Energy-Pass Filter in the Vacuum Ultraviolet Photon Energy Range. J. Vac. Sci. Tech. A 2000, 18, 2533-2541.

(47) Werner, H.-J.; Knowles, P. J.; Knizia, G.; Manby, F. R.; Schütz, M. MOLPRO, Version 2012.1, a Package of Ab Initio Programs, Cardiff University: Cardiff, UK, 2012.

(48) Western, C. M.; Billinghurst, B. E. Automatic Assignment and Fitting of Spectra with PGOPHER. Phys. Chem. Chem. Phys. 2017, 19, 10222-10226. 


\section{$\mathrm{B}_{2} \mathrm{H}_{6}+4 \mathrm{~F} \cdot \longrightarrow \mathrm{H}-\dot{\mathrm{B}}-\dot{\mathrm{B}}-\mathrm{H}+4 \mathrm{HF}$ \\ 2

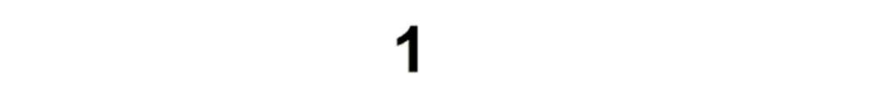

Scheme 1

$71 \times 13 \mathrm{~mm}(300 \times 300$ DPI $)$

ACS Paragon Plus Environment 


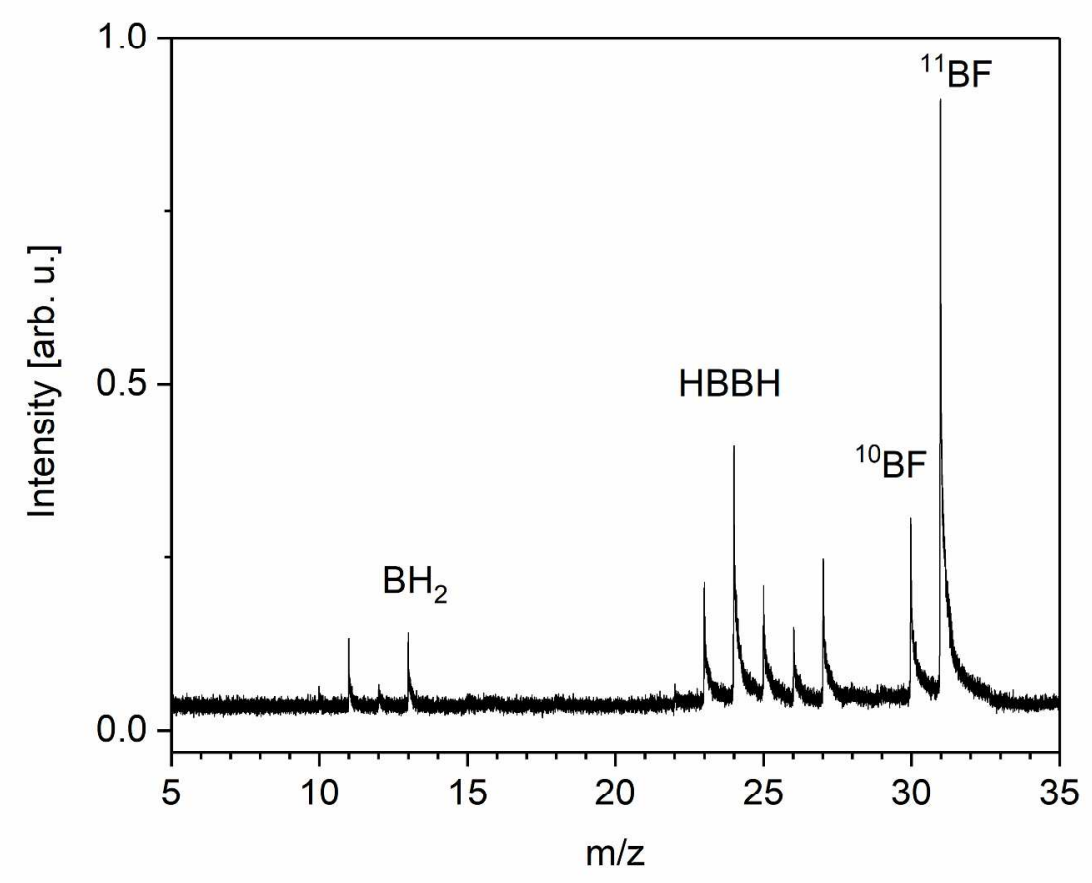

Figure_1

$272 \times 208 \mathrm{~mm}(300 \times 300$ DPI $)$ 


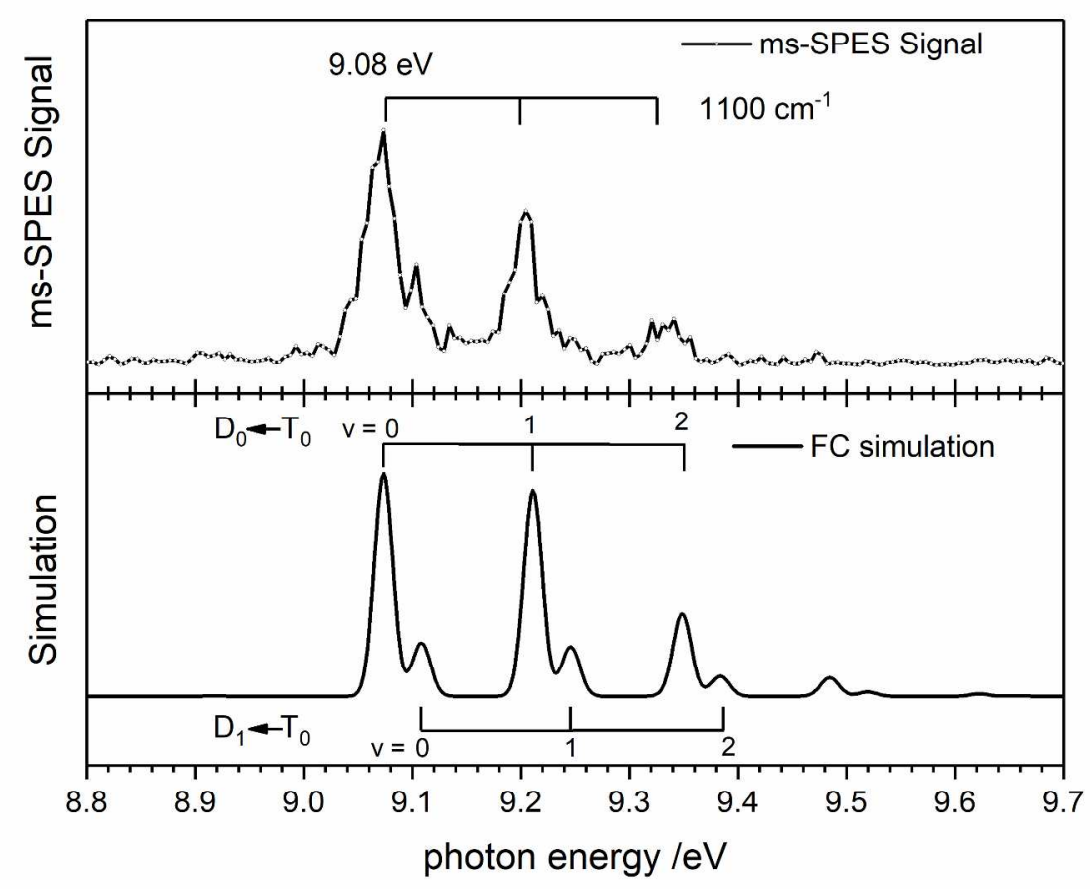

Figure_3

$272 \times 208 \mathrm{~mm}(300 \times 300 \mathrm{DPI})$ 


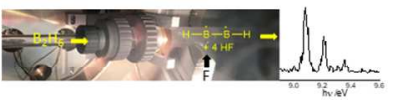

56

57

58

59 